\title{
Renal Blood Flow Response to Angiotensin 1-7 versus Hypertonic Sodium Chloride 7.5\% Administration after Acute Hemorrhagic Shock in Rats
}

\author{
Maryam Maleki ${ }^{1}$ and Mehdi Nematbakhsh ${ }^{1,2,3}$ \\ ${ }^{1}$ Water and Electrolytes Research Center, Isfahan University of Medical Sciences, Isfahan 81745, Iran \\ ${ }^{2}$ Department of Physiology, Isfahan University of Medical Sciences, Isfahan 81745, Iran \\ ${ }^{3}$ Isfahan MN Institute of Basic and Applied Sciences Research, Isfahan 81745, Iran \\ Correspondence should be addressed to Mehdi Nematbakhsh; nematbakhsh@med.mui.ac.ir
}

Received 29 October 2015; Revised 4 February 2016; Accepted 17 February 2016

Academic Editor: Karl A. Illig

Copyright ( $) 2016$ M. Maleki and M. Nematbakhsh. This is an open access article distributed under the Creative Commons Attribution License, which permits unrestricted use, distribution, and reproduction in any medium, provided the original work is properly cited.

\begin{abstract}
Background. Angiotensin 1-7 (Ang1-7) plays an important role in renal circulation. Hemorrhagic shock (HS) may cause kidney circulation disturbance, and this study was designed to investigate the renal blood flow (RBF) response to Ang1-7 after HS. Methods. 27 male Wistar rats were subjected to blood withdrawal to reduce mean arterial pressure (MAP) to $45 \mathrm{mmHg}$ for $45 \mathrm{~min}$. The animals were treated with saline (group 1), Ang1-7 (300 ng. $\mathrm{kg}^{-1} \mathrm{~min}^{-1}$ ), Ang1-7 in hypertonic sodium chloride 7.5\% (group 3), and hypertonic solution alone (group 4). Results. MAP was increased in a time-related fashion $\left(P_{\text {time }}<0.0001\right)$ in all groups; however, there was a tendency for the increase in MAP in response to hypertonic solution $(P=0.09)$. Angl-7, hypertonic solution, or combination of both increased RBF in groups $2-4$, and these were significantly different from saline group $(P=0.05)$; that is, Ang1-7 leads to a significant increase in RBF to $1.35 \pm 0.25 \mathrm{~mL} / \mathrm{min}$ compared with $0.55 \pm 0.12 \mathrm{~mL} / \mathrm{min}$ in saline group $(P<$ 0.05). Conclusion. Although Ang1-7 administration unlike hypertonic solution could not elevate MAP after HS, it potentially could increase RBF similar to hypertonic solution. This suggested that Ang1-7 recovers RBF after HS when therapeutic opportunities of hypertonic solution are limited.
\end{abstract}

\section{Introduction}

Hypovolemic shock, a condition in which tissue perfusion is disturbed to sustain aerobic metabolism [1], occurs due to improper low intravascular volume leading to decrease preload, stroke volume, and cardiac output $[2,3]$. Hemorrhagic shock (HS) usually happens when trauma is accompanied with intense blood loss, and in such condition the management of the patients is complex and difficult [47]. HS causes poor tissue oxygenation and accumulation of oxygen debt that can lead to multiorgan failure $[8,9]$ and increases the morbidity rate [10]. On the other hand the kidney function directly depends on renal perfusion pressure (RPP) and this organ is particularly sensitive to HS [11]. HS exacerbates renal damage via decreasing oxygen delivery to the kidney induced hypoxia [12-14] which induces acute kidney injury (AKI) [15]. Delayed diagnosis and treatment may increase morbidity and mortality rates [16]. Therefore during HS necessary interventions are needed to prevent the organ deterioration and function [17].

Renin angiotensin system (RAS) has a pivotal role in kidney function, and it adjusts the body fluid and blood pressure $[18,19]$. This system shows both roles of vasoconstriction and vasodilation in kidney and systematic vascular bed, which depend on angiotensin converting enzymes 1 and 2 (ACE1 and ACE2) levels [20, 21]. Angiotensin (Ang) I is hydrolyzed to Ang II via ACE, while hydrolysis of Ang II by ACE2 generates Ang1-7 that subsequently acts upon the Mas receptor [22, 23]. Ang1-7 stimulates nitric oxide (NO) production that may or may not depend on the release of bradykinin $[24,25]$. It may also act directly via increasing of prostaglandins to exert the vasodilatory and natriuretic actions [26]. Acute infusion of Ang1-7 increases the glomerular filtration rate (GFR) and renal blood flow 
$(\mathrm{RBF})$, and it is reported that, in preconstricted afferent arterioles of the rabbit kidney, Ang1-7 induces vasodilation depending on NO [27]. Due to limited use of hypertonic solution in HS, we hypothesized that Ang1-7 administration may promote renal hemodynamic parameters after HS. To test this hypothesis, the RBF responses to Ang1-7, sodium chloride hypertonic solution, or combination of both Ang1-7 plus hypertonic solution compared with vehicle infusion were determined after HS in rats.

\section{Methods and Materials}

2.1. Animals. This study was approved in advance by the Ethics Committee of the Isfahan University of Medical Sciences. 27 male Wistar rats weighting 230 to $270 \mathrm{~g}$ from Water and Electrolyte Research Center Animal House were used. The animals were housed at a room temperature of $24 \pm$ $1^{\circ} \mathrm{C}$ with a 12-hour light/dark cycle and fed with rat chow and water ad libitum and allowed 1 week to acclimatize to these conditions.

2.2. Surgical Preparation. The animals were anesthetized with urethane (1.7 g. $\mathrm{kg}^{-1}$ i.p.; Merck, Germany), and the trachea was cannulated to facilitate air ventilation. Animals were placed in lateral position on a surgical table with heating lamp to control body temperature between $36.5^{\circ}$ and $37.5^{\circ} \mathrm{C}$. The left jugular vein was exposed, ligated distally, and cannulated with polyethylene tube to infuse the solutions. The left femoral artery was catheterized and the catheter was driven forward into the abdominal aorta below the renal arteries to measure direct blood pressure. The femoral catheter was attached to a pressure transducer and a bridge amplifier (Scientific Concepts, Vic., Melbourne, Australia) to measure mean arterial pressure (MAP) (in fact, we considered renal perfusion pressure as MAP). In order to induce HS, carotid artery was catheterized for blood withdrawal. The bladder also was catheterized to collect urine output. The left kidney was exposed and placed in a cup secured to the operating table. The left renal artery was surrounded by a transit-time ultrasound flow probe (Type 2SB; Transonic Systems, Ithaca, NY, USA) interfaced with a compatible flowmeter (T108; Transonic Systems) to measure direct RBF. Throughout the experiment MAP and RBF were measured continuously and data were recorded as two-second averages via a data acquisition system.

\subsection{Experimental Protocol. After 30-minute stabilization} period, rats underwent controlled HS at MAP $45 \mathrm{mmHg}$ for a period of 45 minutes. Blood withdrawal was carried out in two phases: blood was withdrawn first in $10 \mathrm{~min}$ to stabilize MAP at $45 \mathrm{mmHg}$ and second when MAP > 45. The total blood volume withdrawn was measured, and the animals were randomly assigned into the following treatment groups. Group $1(n=7)$ as control was subjected to treatment with vehicle (saline). Groups $2(n=6), 3(n=9)$, and $4(n=$ 5) as treated groups received Ang1-7 (300 ng. kg-1 in saline), Ang1-7 in hypertonic sodium chloride $7.5 \%(5 \mathrm{~mL} / \mathrm{kg})$, and hypertonic solution alone. The dose of Ang1-7 (300 ng/kg) was selected based on previous studies to have at least 10 percent change in renal blood flow $[28,29]$. The prepared volume of the each infused fluid was equal to the volume of blood withdrawal during HS. The infused fluid was administered as a continuous infusion during the $15 \mathrm{~min}$. Animals were monitored for another $15 \mathrm{~min}$ after infusion, and MAP and RBF were measured continuously as described above. Renal vascular resistance was calculated by RPP/RBF ratio.

2.4. Statistical Analysis. Data are expressed as mean \pm SEM. ANOVA test was applied to analyze the urine weight and serum nitrite level. Repeated measures ANOVA was used to compare the effect of each treatment between groups. $P$ value $<0.05$ was considered statistically significant.

\section{Results}

3.1. Baseline Measurements. The data for MAP, RVR, and RBF were corrected for kidney weight before induction of the HS as basal measurement is tabulated in Table 1 . The statistical analyses indicated no significant differences between the groups in basal measurement.

3.2. Blood Volume Withdrawal during HS. The animal weights were recorded as $223.0 \pm 8.4,243.2 \pm 11.9,232.5 \pm 3.6$, and $228.4 \pm 8.2 \mathrm{~g}$, and the volumes of blood withdrawal to induce HS were $3.0 \pm 0.25,3.3 \pm 0.20,3.5 \pm 0.19$, and $3.4 \pm$ $0.26 \mathrm{~mL}$ in groups 1 to 4 , respectively. There is no statistical difference between the groups in weight $(P=0.36)$ and blood volume withdrawal $(P=0.37)$.

3.3. RBF Response to Ang1-7, Sodium Chloride Hypertonic Solution, or Vehicle. As blood volume was withdrawn, MAP reduced to about $45 \mathrm{mmHg}$ to induce HS. This pressure was controlled at constant level during 45 min of shock by blood withdrawal. MAP and RBF responses to vehicle, Ang17, Ang1-7 plus hypertonic solution, and hypertonic solution alone infusion are shown in Figure 1. MAP and RBF were increased by all the treatment solutions significantly $\left(P_{\text {time }}<\right.$ 0.0001). As expected, hypertonic solution provided a better increment for MAP and RBF. However no significant differences were detected in MAP response between the groups. RBF response to Ang1-7, Ang1-7 plus hypertonic solution, and hypertonic solution alone were statistically different from that in vehicle treated group $(P=0.05)$. For example at $5 \mathrm{~min}$ after infusion, the RBF response to Ang1-7, Ang1-7 plus hypertonic solution, and hypertonic solution alone were $1.36 \pm 0.25$, $1.37 \pm 0.23$, and $1.37 \pm 0.14 \mathrm{~mL} / \mathrm{min} / \mathrm{g}$ tissue while this response to vehicle administration was $0.56 \pm 0.12 \mathrm{~mL} / \mathrm{min} / \mathrm{g}$ tissue $(P<0.05)$. RVR response during $30 \mathrm{~min}$ of shock could not be determined due to the lowest RBF. However, postinfusion records indicated that RVR response in vehicle treated group was greater than other groups insignificantly $(P=0.27)$.

3.4. Serum Nitrite Level and Urine Weight. During post shock, from starting of infusion until end of experiment 
TABLE 1: Baseline hemodynamic parameters in 4 experimental groups.

\begin{tabular}{lccc}
\hline Group & & Factor & \\
& MAP $(\mathrm{mmHg})$ & $\mathrm{RBF}(\mathrm{mL} / \mathrm{min} / \mathrm{g}$ tissue $)$ & $\mathrm{RVR}(\mathrm{mmHg} /(\mathrm{mL} / \mathrm{min} / \mathrm{g}$ tissue $))$ \\
\hline Saline & $89.65 \pm 5.96$ & $1.23 \pm 0.05$ & $74.04 \pm 6.07$ \\
Ang1-7 & $83.42 \pm 4.71$ & $1.46 \pm 0.18$ & $65.72 \pm 15.14$ \\
Ang1-7 + hypertonic & $92.48 \pm 5.69$ & $1.27 \pm 0.12$ & $78.04 \pm 8.62$ \\
Hypertonic & $80.38 \pm 5.07$ & $1.59 \pm 0.33$ & $49.30 \pm 9.00$ \\
$P$ & 0.51 & 0.36 & 0.25 \\
\hline
\end{tabular}

Data are presented as mean \pm SEM. MAP; mean arterial pressure, RVR; renal vascular resistance, RBF; renal blood flow per gram kidney weight, Angl-7; angiotensin 1-7. There were no significant differences between the groups. $P$ values were derived from ANOVA.
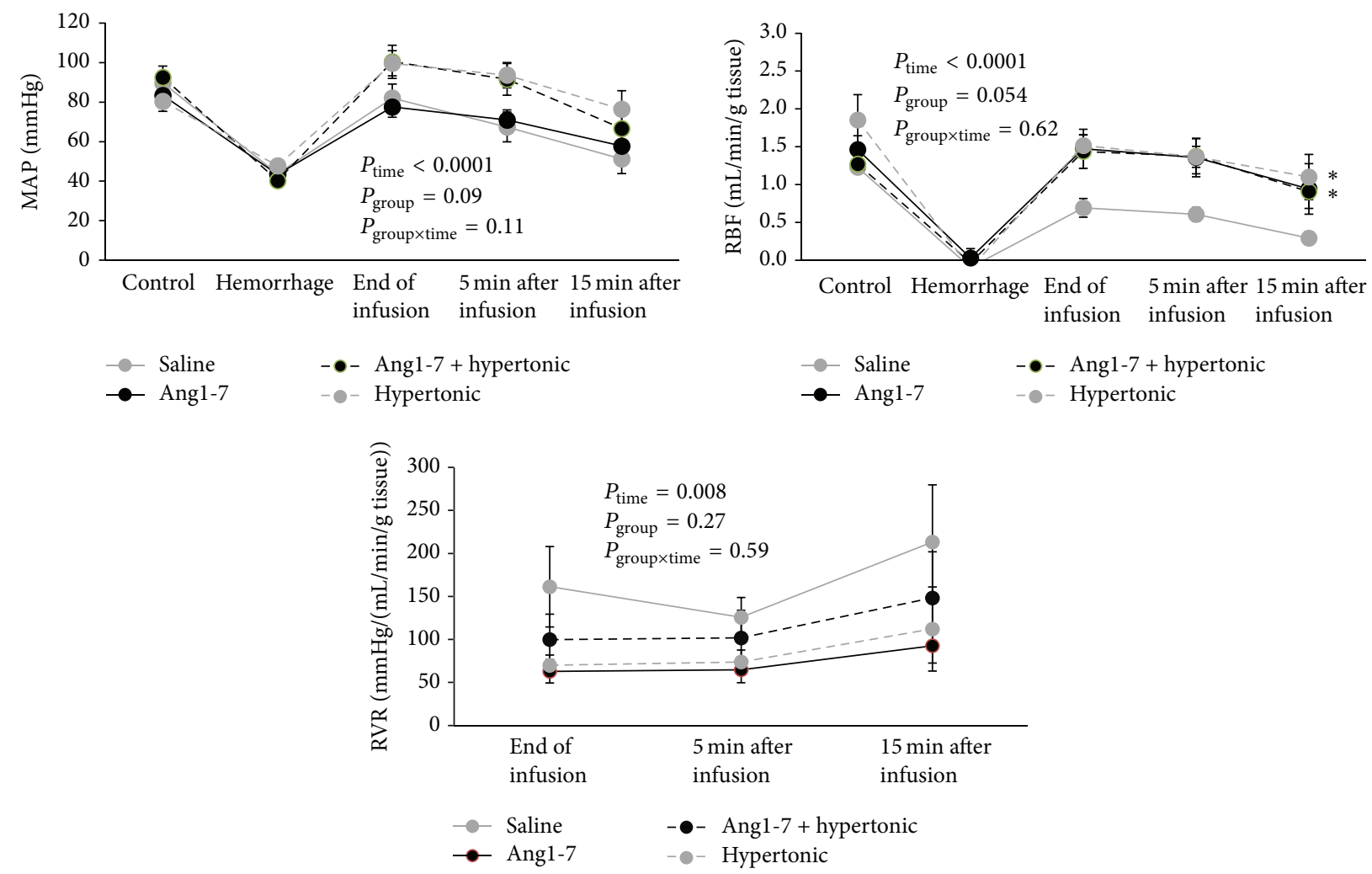

FIGURE 1: MAP, RBF, and RVR responses to saline, Ang1-7, Ang1-7 + hypertonic saline, and hypertonic saline alone administration after 45 min hemorrhagic shock. Data are shown as mean \pm SEM. MAP, mean arterial pressure; RBF, renal blood flow; RVR, renal vascular resistance. * means significant difference between vehicle and the other groups. $P$ values were derived from repeated measures for ANOVA.

the urine was collected and weighted. The result indicated that the urine responses to Angl-7 infusion were statistically greater than saline group $(P<0.05)$ (Figure 2). To consider nitrite level, no significant differences were observed between the groups neither before nor after the treatments.

\section{Discussion}

Low cardiac output and MAP are considered as predictors of poor outcome in patients which reduces RBF and disturbs kidney functions [30, 31]. Restoration of the hemodynamic status is pivotal for RBF recovery after HS [32]. In this study, RBF responses to different solutions administration in a HS model were determined. RBF responses to Ang1-7, Ang1-7 plus hypertonic solution and hypertonic solution alone were statistically different from that in vehicle treated group while there was a tendency for increasing MAP in response to hypertonic solution groups more than Ang1-7 and vehicle treated groups. In addition, coadministration of Ang1-7 and hypertonic solution did not result in a synergistic effect on RBF compared to administration of Angl-7 or hypertonic saline alone.

It is expected that both saline and hypertonic solutions produce plasma expansion, blood pressure, and GFR elevation [33]. The suitable MAP level is pivotal to preserve renal function, and at a specific level of MAP, RBF decreases and causes AKI [34]. However, the exact minimum level of MAP to prevent the kidney disturbance still remains unknown [34]. It is reported that MAP above $65 \mathrm{mmHg}$ might be 


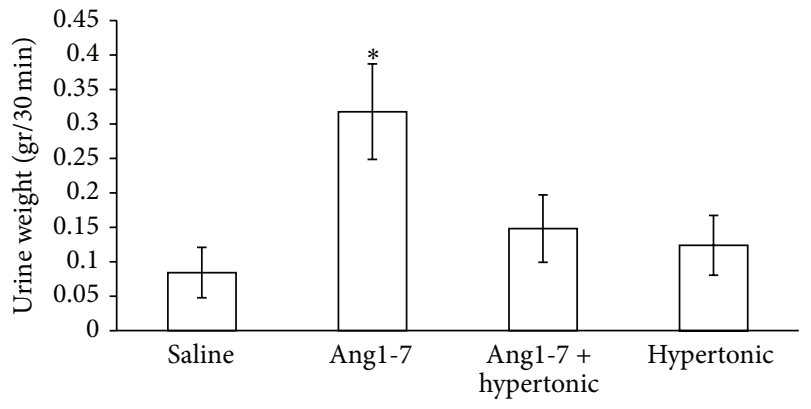

(a)

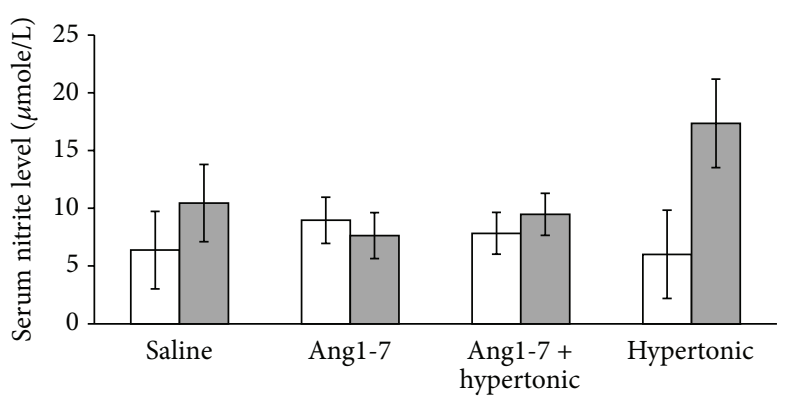

口 Before shock

口 After shock

(b)

Figure 2: (a) Urine weight response to saline, Ang1-7, Ang1-7 + hypertonic saline, and hypertonic saline alone administration. (b) Serum nitrite level before hemorrhagic shock and 30 minutes after administration of saline, Ang1-7, Ang1-7 + hypertonic saline, and hypertonic saline alone from the end of hemorrhagic shock. Data are shown as mean \pm SEM. Ang1-7, Angiotensin 1-7; *, means significant difference between Ang1-7 and saline. $P$ value was derived from ANOVA.

necessary to prevent AKI [35]. Patients with low MAP who also received the highest doses of vasopressors are significantly linked to AKI occurrence [34]. The vasodepressor effect of Ang1-7 mediated by prostaglandins and NO [3638], and Ang1-7 and its signaling pathways may antagonize the actions of AngII type 1 receptor [39, 40]. One point is important here; the lower concentrations of Ang1-7 are required to stimulate $\mathrm{NO}$ compared to that for Ang II acting via the Ang II type 2 vasodilatory receptor [41-43]. Acute administration of Ang1-7 enhances GFR and RBF that reflects the vasorelaxant properties [27]. Ang1-7 also shows the ability to stimulate the formation of NO [44, 45], and it stimulates the phosphorylation of eNOS and the associated kinase Akt in endothelial cells [24]. In addition and similar to bradykinin, Ang1-7 shows a pathway that releases NO [46], and the vasorelaxant actions of Ang1-7 may be reflected by the release of vasoactive prostaglandins, prostacyclin, and PGE2 [47]. It was also reported that the systemically hypotensive effectiveness of Ang1-7 administration was greater in spontaneously hypertensive and renovascular hypertensive than normotensive animal models [37, 48, 49]. Ang1-7 also involves vasopressin release. It is reported that Ang1-7 receptor antagonist (A779) decreased NO concentration to restore the risen vasopressin levels during hemorrhagic shock [50], and it also interacts with the vasopressin V2 receptor [51]. In addition Ang-(1-7) as a potent antidiuretic peptide $[52,53]$ also influences water excretion [54] possibly by effect on vasopressin system.

Our data from serum nitrite level did not support NO formation by Ang1-7 administration; however it still seems that Ang1-7 increased RBF via formation of NO [44, 45] possibly within the kidney. Our result also did not show the synergistic effect from Ang1-7 plus hypertonic solution because hypertonic solution is liable for large transcapillary absorptive forces which exert maximum intravascular volume expansion immediately at the end of infusion [55] to increase MAP, organ flow, and urine output [56]. MAP elevation by hypertonic solution may increase vascular resistance as Nakamoto et al. reported that hypertension is accompanied with increase of vascular resistance by NO-dependent mechanism created through vascular endothelium [37], and this phenomenon may limit the production of NO by Ang1-7.

\section{Conclusion}

Ang1-7 potentially could increase RBF and urine output due to RVR decreasing after HS. However increased MAP by isotonic normal saline containing Ang1-7 after HS is not similar to sodium chloride hypertonic solution.

\section{Competing Interests}

The authors declare that they have no competing interests.

\section{Acknowledgments}

This research was supported by Isfahan University of Medical Sciences. The authors thank Ms Zahra Pezeshki for her technical assistance.

\section{References}

[1] G. Gutierrez, H. D. Reines, and M. E. Wulf-Gutierrez, "Clinical review: hemorrhagic shock," Critical Care, vol. 8, no. 5, pp. 373381, 2004.

[2] C. P. Boyan, "Hypovolemic shock," Anesthesia \& Analgesia, vol. 46, no. 6, pp. 746-750, 1967.

[3] W. Schumer, "Hypovolemic shock," The Journal of the American Medical Association, vol. 241, no. 6, pp. 615-616, 1979.

[4] M. Heron, D. Hoyert, S. Murphy, J. Xu, K. Kochanek, and B. Tejada-Vera, "Deaths: final data for 2006," National Vital Statistics Reports, vol. 57, article 14, 2009.

[5] K. K. Nandra, M. Collino, M. Rogazzo, R. Fantozzi, N. S. A. Patel, and C. Thiemermann, "Pharmacological preconditioning with erythropoietin attenuates the organ injury and dysfunction 
induced in a rat model of hemorrhagic shock," Disease Models \& Mechanisms, vol. 6, no. 3, pp. 701-709, 2013.

[6] D. S. Kauvar and C. E. Wade, "The epidemiology and modern management of traumatic hemorrhage: US and international perspectives," Critical Care, vol. 9, supplement 5, pp. S1-S9, 2005.

[7] A. Bouglé, A. Harrois, and J. Duranteau, "Resuscitative strategies in traumatic hemorrhagic shock," Annals of Intensive Care, vol. 3, no. 1, article 1, 2013.

[8] B. J. Baron and T. M. Scalea, "Acute blood loss," Emergency Medicine Clinics of North America, vol. 14, no. 1, pp. 35-55, 1996.

[9] M. Wilson, D. P. Davis, and R. Coimbra, "Diagnosis and monitoring of hemorrhagic shock during the initial resuscitation of multiple trauma patients: a review," The Journal of Emergency Medicine, vol. 24, no. 4, pp. 413-422, 2003.

[10] E. E. Douzinas, "Hemorrhagic shock resuscitation: a critical issue on the development of posttraumatic multiple organ failure," Critical Care Medicine, vol. 40, no. 4, pp. 1348-1349, 2012.

[11] M. Hultström, "Neurohormonal interactions on the renal oxygen delivery and consumption in haemorrhagic shock-induced acute kidney injury," Acta Physiologica, vol. 209, no. 1, pp. 11-25, 2013.

[12] L. S. Nuutinen, S. Tuononen, M. Kairaluoma, T. K. Larmi, and A. Hollmen, "Plasma renin activity, renal artery blood flow and cortical tissue oxygen tension in haemorrhagic hypotension," Annales Chirurgiae et Gynaecologiae, vol. 66, no. 2, pp. 94-97, 1977.

[13] S. Tuononen, L. Nuutinen, A. Hollmen, and T. Larmi, "Renal blood flow and intrarenal oxygen tension in haemorrhagic hypotension," Annales Chirurgiae et Gynaecologiae Supplementum, vol. 66, no. 5, pp. 258-261, 1976.

[14] O. Nelimarkka, "Renal oxygen and lactate metabolism in hemorrhagic shock. An experimental study," Acta Chirurgica Scandinavica, Supplement, vol. 518, pp. 1-44, 1984.

[15] S. N. Heyman, M. Khamaisi, S. Rosen, and C. Rosenberger, "Renal parenchymal hypoxia, hypoxia response and the progression of chronic kidney disease," American Journal of Nephrology, vol. 28, no. 6, pp. 998-1006, 2008.

[16] K. B. Williams, A. B. Christmas, B. T. Heniford, R. F. Sing, and J. Messick, "Arterial vs venous blood gas differences during hemorrhagic shock," World Journal of Critical Care Medicine, vol. 3, no. 2, pp. 55-60, 2014.

[17] D. E. Fry, L. Pearlstein, R. L. Fulton, and H. C. Polk Jr., "Multiple system organ failure: the role of uncontrolled infection," Archives of Surgery, vol. 115, no. 2, pp. 136-140, 1980.

[18] W. C. De Mello and A. H. J. Danser, "Angiotensin II and the heart on the intracrine renin-angiotensin system," Hypertension, vol. 35, no. 6, pp. 1183-1188, 2000.

[19] R. G. Evans, D. S. A. Majid, and G. A. Eppel, "Mechanisms mediating pressure natriuresis: what we know and what we need to find out," Clinical and Experimental Pharmacology and Physiology, vol. 32, no. 5-6, pp. 400-409, 2005.

[20] P. E. Walters, T. A. Gaspari, and R. E. Widdop, "Angiotensin(1-7) acts as a vasodepressor agent via angiotensin II type 2 receptors in conscious rats," Hypertension, vol. 45, no. 5, pp. 960-966, 2005.

[21] R. A. Santos, A. J. Ferreira, and A. C. Simões e Silva, "Recent advances in the angiotensin-converting enzyme 2-angiotensin (1-7)-mas axis," Experimental Physiology, vol. 93, no. 5, pp. 519527, 2008 (Maltese).
[22] P. Corvol, T. A. Williams, and F. Soubrier, "Peptidyl dipeptidase A: angiotensin I-converting enzyme," Methods in Enzymology, vol. 248, pp. 283-305, 1995.

[23] R. A. S. Santos, A. C. Simoes e Silva, C. Maric et al., "Angiotensin-(1-7) is an endogenous ligand for the G protein-coupled receptor Mas," Proceedings of the National Academy of Sciences of the United States of America, vol. 100, no. 14, pp. 8258-8263, 2003.

[24] W. O. Sampaio, R. A. S. dos Santos, R. Faria-Silva, L. T. Da Mata Machado, E. L. Schiffrin, and R. M. Touyz, "Angiotensin-(1-7) through receptor Mas mediates endothelial nitric oxide synthase activation via Akt-dependent pathways," Hypertension, vol. 49, no. 1, pp. 185-192, 2007.

[25] D. Weiss, J. J. Kools, and W. R. Taylor, "Angiotensin II-induced hypertension accelerates the development of atherosclerosis in ApoE-deficient mice," Circulation, vol. 103, no. 3, pp. 448-454, 2001.

[26] S. N. Iyer, K. Yamada, D. I. Diz, C. M. Ferrario, and M. C. Chappell, "Evidence that prostaglandins mediate the antihypertensive actions of angiotensin-(1-7) during chronic blockade of the renin-angiotensin system," Journal of Cardiovascular Pharmacology, vol. 36, no. 1, pp. 109-117, 2000.

[27] Y. Ren, J. L. Garvin, and O. A. Carretero, "Vasodilator action of angiotensin-(1-7) on isolated rabbit afferent arterioles," Hypertension, vol. 39, no. 3, pp. 799-802, 2002.

[28] A. Dehghani, S. Saberi, and M. Nematbakhsh, "Role of mas receptor antagonist A799 in renal blood flow response to Ang 17 after bradykinin administration in ovariectomized estradioltreated rats," Advances in Pharmacological Sciences, vol. 2015, Article ID 801053, 9 pages, 2015.

[29] M. Nematbakhsh and T. Safari, "Role of Mas receptor in renal blood flow response to angiotensin (1-7) in male and female rats," General Physiology and Biophysics, vol. 33, no. 3, pp. 365372, 2014.

[30] S. R. Heckbert, N. B. Vedder, W. Hoffman et al., "Outcome after hemorrhagic shock in trauma patients," The Journal of Trauma, vol. 45, no. 3, pp. 545-549, 1998.

[31] C. Langenberg, R. Bellomo, C. May, L. Wan, M. Egi, and S. Morgera, "Renal blood flow in sepsis," Critical Care, vol. 9, no. 4, article R363, 2005.

[32] J. L. Sondeen, G. A. Gonzaludo, J. A. Loveday, W. G. Rodkey, and C. E. Wade, "Hypertonic saline/dextran improves renal function after hemorrhage in conscious swine," Resuscitation, vol. 20, no. 3, pp. 231-241, 1990.

[33] P. Nascimento Jr., O. de Paiva Filho, L. R. de Carvalho, and J. R. C. Braz, "Early hemodynamic and renal effects of hemorrhagic shock resuscitation with lactated Ringer's solution, hydroxyethyl starch, and hypertonic saline with or without $6 \%$ dextran-70," Journal of Surgical Research, vol. 136, no. 1, pp. 98105, 2006.

[34] J. Badin, T. Boulain, S. Ehrmann et al., "Relation between mean arterial pressure and renal function in the early phase of shock: a prospective, explorative cohort study," Critical Care, vol. 15, no. 3, article R135, 2011.

[35] M. W. Dünser, E. Ruokonen, V. Pettilä et al., "Association of arterial blood pressure and vasopressor load with septic shock mortality: a post hoc analysis of a multicenter trial," Critical Care, vol. 13, no. 6, article R181, 2009.

[36] N. Jaiswal, R. K. Jaiswal, E. A. Tallant, D. I. Diz, and C. M. Ferrario, "Alterations in prostaglandin production in spontaneously hypertensive rat smooth muscle cells," Hypertension, vol. 21, no. 6, part 2, pp. 900-905, 1993. 
[37] H. Nakamoto, C. M. Ferrario, S. B. Fuller, D. L. Robaczewski, E. Winicov, and R. H. Dean, "Angiotensin-(1-7) and nitric oxide interaction in renovascular hypertension," Hypertension, vol. 25, no. 4, pp. 796-802, 1995.

[38] I. Porsti, A. T. Bara, R. Busse, and M. Hecker, "Release of nitric oxide by angiotensin-(1-7) from porcine coronary endothelium: implications for a novel angiotensin receptor," British Journal of Pharmacology, vol. 111, no. 3, pp. 652-654, 1994.

[39] M. C. Chappell, "Emerging evidence for a functional angiotensin-converting enzyme 2-angiotensin-(1-7)-mas receptor axis more than regulation of blood pressure?" Hypertension, vol. 50, no. 4, pp. 596-599, 2007.

[40] C. M. Ferrario, "Angiotensin-converting enzyme 2 and angiotensin-(1-7): an evolving story in cardiovascular regulation," Hypertension, vol. 47, no. 3, pp. 515-521, 2006.

[41] T. M. Gwathmey, K. D. Pendergrass, S. D. Reid, J. C. Rose, D. I. Diz, and M. C. Chappell, "Angiotensin-(1-7)-angiotensinconverting enzyme 2 attenuates reactive oxygen species formation to angiotensin II within the cell nucleus," Hypertension, vol. 55, no. 1, pp. 166-171, 2010.

[42] T. M. Gwathmey, H. A. Shaltout, J. C. Rose, D. I. Diz, and M. C. Chappell, "Glucocorticoid-induced fetal programming alters the functional complement of angiotensin receptor subtypes within the kidney," Hypertension, vol. 57, no. 3, pp. 620-626, 2011.

[43] T. M. Gwathmey, B. M. Westwood, N. T. Pirro et al., "Nuclear angiotensin-(1-7) receptor is functionally coupled to the formation of nitric oxide," The American Journal of Physiology-Renal Physiology, vol. 299, no. 5, pp. F983-F990, 2010.

[44] H. Heitsch, S. Brovkovych, T. Malinski, and G. Wiemer, "Angiotensin-(1-7)-stimulated nitric oxide and superoxide release from endothelial cells," Hypertension, vol. 37, no. 1, pp. 72-76, 2001.

[45] G. Wiemer, L. W. Dobrucki, F. R. Louka, T. Malinski, and H. Heitsch, "AVE 0991, a nonpeptide mimic of the effects of angiotensin-(1-7) on the endothelium," Hypertension, vol. 40, no. 6, pp. 847-852, 2002.

[46] M. C. Chappell, "Nonclassical renin-angiotensin system and renal function," Comprehensive Physiology, vol. 2, no. 4, pp. 2733-2752, 2012.

[47] M. C. Chappell, J. Gregory Modralt, D. I. Diz, and C. M. Ferrario, "Novel aspects of the renal renin-angiotensin system: angiotensin-(1-7), ACE2 and blood pressure regulation," Contributions to Nephrology, vol. 143, pp. 77-89, 2004.

[48] I. F. Benter, D. I. Diz, and C. M. Ferrario, "Pressor and reflex sensitivity is altered in spontaneously hypertensive rats treated with angiotensin-(1-7)," Hypertension, vol. 26, no. 6, pp. 11381144, 1995.

[49] I. F. Benter, C. M. Ferrario, M. Morris, and D. I. Diz, "Antihypertensive actions of angiotensin-(1-7) in spontaneously hypertensive rats," American Journal of Physiology-Heart and Circulatory Physiology, vol. 269, no. 1, pp. H313-H319, 1995.

[50] A. M. Whitaker and P. E. Molina, "Angiotensin (1-7) contributes to nitric oxide tonic inhibition of vasopressin release during hemorrhagic shock in acute ethanol intoxicated rodents," Life Sciences, vol. 93, no. 17, pp. 623-629, 2013.

[51] A. J. Magaldi, K. R. Cesar, M. de Araújo, A. C. Simões e Silva, and R. A. S. Santos, "Angiotensin-(1-7) stimulates water transport in rat inner medullary collecting duct: evidence for involvement of vasopressin $\mathrm{V}_{2}$ receptors," Pflügers Archiv, vol. 447, no. 2, pp. 223-230, 2003.
[52] R. A. Santos and N. C. Baracho, "Angiotensin-(1-7) is a potent antidiuretic peptide in rats," Brazilian Journal of Medical and Biological Research, vol. 25, no. 6, pp. 651-654, 1992.

[53] M. T. Schiavone, R. A. S. Santos, K. B. Brosnihan, M. C. Khosla, and C. M. Ferrario, "Release of vasopressin from the rat hypothalamo-neurohypophysial system by angiotensin-(1-7) heptapeptide," Proceedings of the National Academy of Sciences of the United States of America, vol. 85, no. 11, pp. 4095-4098, 1988.

[54] R. A. S. Santos, A. C. Simões e Silva, A. J. Magaldi et al., "Evidence for a physiological role of angiotensin-(1-7) in the control of hydroelectrolyte balance," Hypertension, vol. 27, no. 4, pp. 875-884, 1996.

[55] G. C. Kramer, G. I. Elgjo, L. F. Poli de Figueiredo, and C. E. Wade, "Hyperosmotic-hyperoncotic solutions," Baillière's Clinical Anaesthesiology, vol. 11, no. 1, pp. 143-161, 1997.

[56] S.-I. Nakayama, L. Sibley, and R. A. Gunther, "Small-volume resuscitation with hypertonic saline $(2,400 \mathrm{mOsm} / \mathrm{liter})$ during hemorrhagic shock," Circulatory Shock, vol. 13, no. 2, pp. 149159, 1983. 


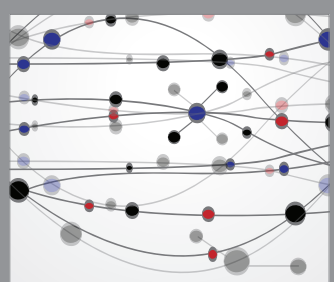

The Scientific World Journal
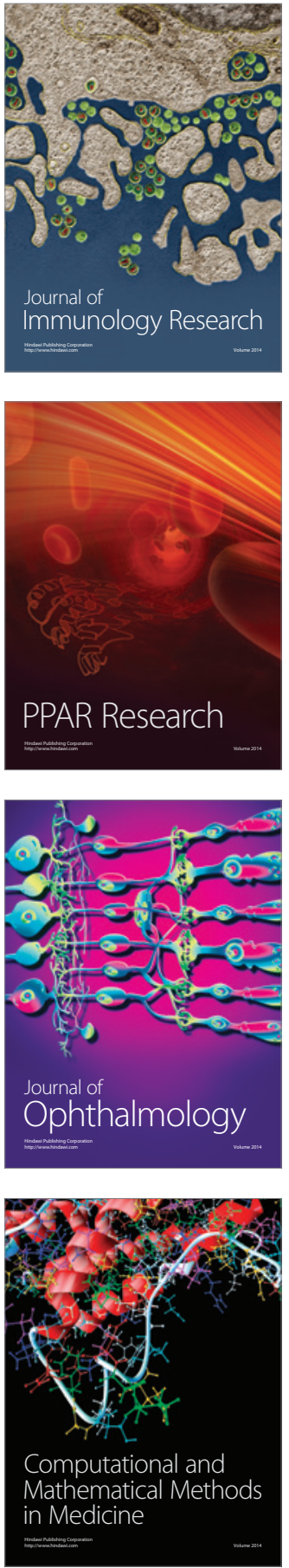

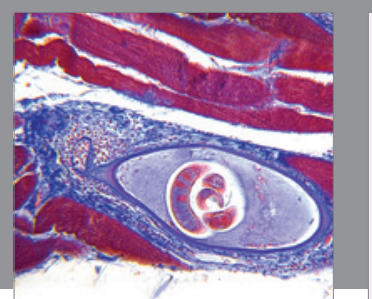

Gastroenterology Research and Practice

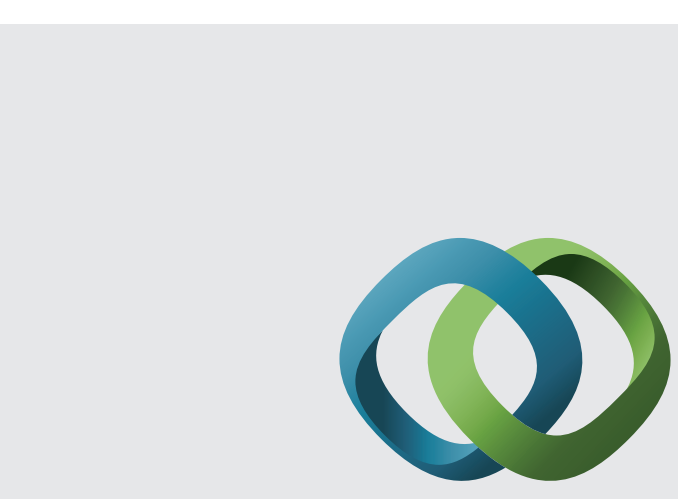

\section{Hindawi}

Submit your manuscripts at

http://www.hindawi.com
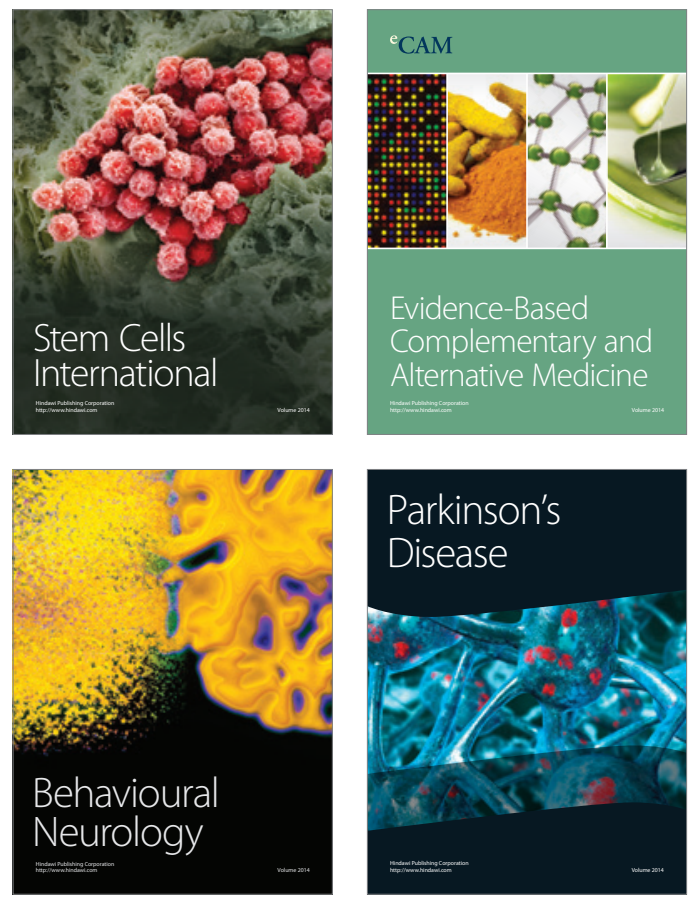
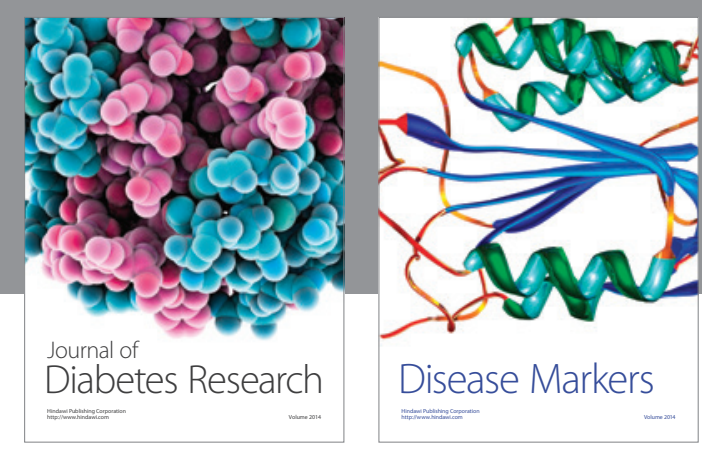

Disease Markers
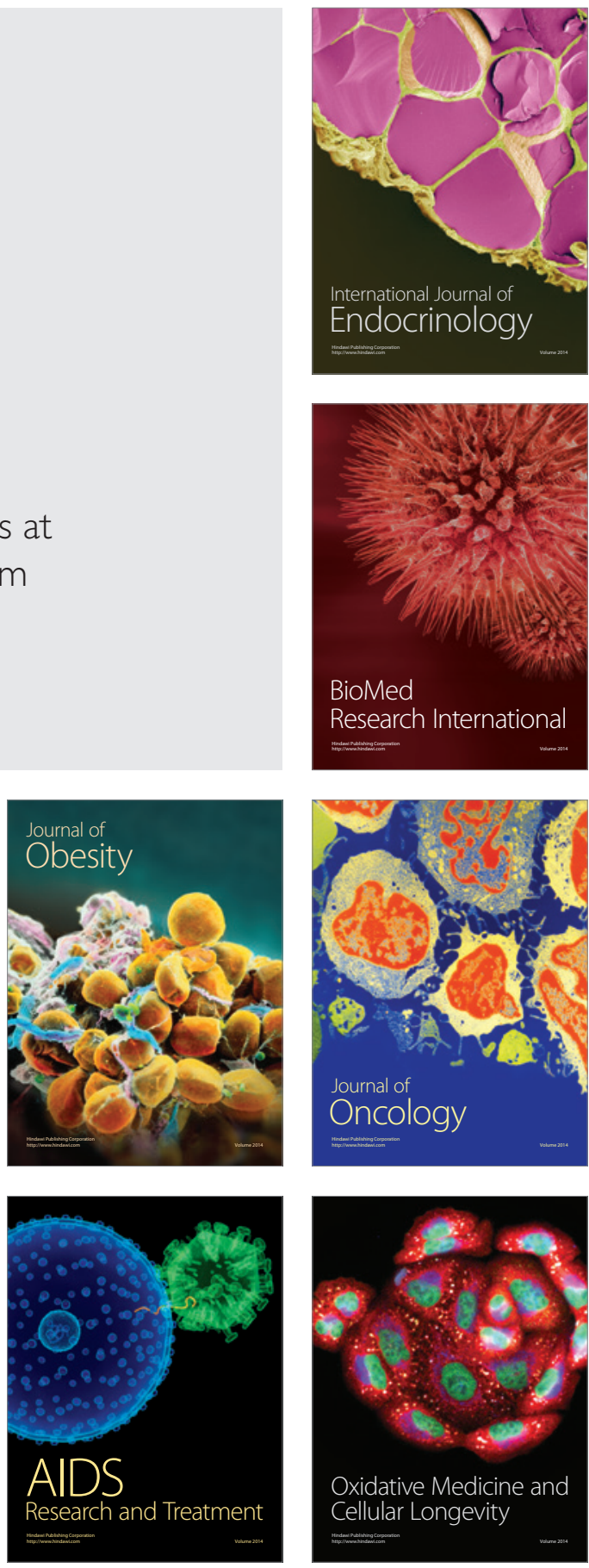